\title{
Development of radiation dosimetric phantoms made from SPC/NaOH/IA-PAE/Rhizophora spp. particleboards
}

\author{
D.O. Samson ${ }^{1,3}{ }^{*}$, A. Shukri', M.Z. Mat Jafri ${ }^{*}$, R. Hashim², M.Z.A. Aziz ${ }^{3}$, \\ M.F.M. Yusof 4
}

${ }^{1}$ School of Physics, Universiti Sains Malaysia, 11800 Penang, Malaysia

${ }^{2}$ School of Industrial Technology, Universiti Sains Malaysia, 11800 Penang, Malaysia

${ }^{3}$ Advanced Medical and Dental Institute, Universiti Sains Malaysia, 13200 Bertam, Penang, Malaysia

${ }^{4}$ School of Health Sciences, Universiti Sains Malaysia, 16150 Kota Bharu, Kelantan, Malaysia

\section{- Original article}

*Corresponding authors:
Damilola O. Samson, Ph.D.,
E-mail:
saamdoftt82@gmail.com
M.Z. Mat Jafri, Ph.D.,
E-mail: mjafri@usm.my
Revised: January 2021
Accepted: February 2021
Int. J. Radiat. Res., October 2021;
19(4): $801-811$
DOI: 10.29242/ijrr.19.4.801

\begin{abstract}
Background: The present study aims to investigate and characterize radiation dosimetric phantom that is made from Rhizophora spp. particleboards using SPC/NaOH/IA-PAE adhesive. Materials and Methods: Modification of soy protein concentrate (SPC) bonded Rhizophora spp. particleboard phantoms were carried out using sodium hydroxide $(\mathrm{NaOH})$ with different amount of bio -based cross-linking agent (IA-PAE) with three different categories of particle size. The radiation attenuation parameters were evaluated with photons energies between 16.59 and $25.26 \mathrm{keV}$ derived from X-ray fluorescence. SPCbased plug phantoms were scanned together with the $\mathrm{CT}$ density phantom $062 \mathrm{M}$ at 80, 120, and $135 \mathrm{kVp}$, and $250 \mathrm{mAs}$. Results: The physical and mechanical properties were found to be improved, while the dimensional stability was decreased through the addition of 15 wt\% IA-PAE with decreasing particle size. The lowest HVL and MFP, and the highest $\mu_{\mathrm{m}}$ with their corresponding values of $Z_{\text {eff }}(p$-values of $0.054,0.055,0.060$, and 0.075 ), and the relatively low $X^{2}$ values are the characteristics of samples labeled as $A_{15}, B_{15}, C_{10}$, and $C_{15}$. Sample $C_{15}$ gave the closest values of $C T$ number, $E D$, and DDPs to water for all tested tube voltages. Conclusion: The results point to the possibility of employing $C_{15}$ as a promising TEPM.
\end{abstract}

Keywords: Computed tomography system, RAPs, SPC, rhizophora spp., phantom material.

\section{INTRODUCTION}

In the last few decades, an intense study on the dosimetric properties of various homogeneous phantom materials has been carried out. This was done in the quest of discovering suitable solid tissue-equivalent phantom materials (TEPMs) that would replace water phantom, because of the limitation water poses when applied in conjunction with detectors that are not waterproof. This was in addition to the challenge of localization of the radiation detectors in water $(1,2)$. However, the use of solid TEPMs is still short of providing good agreement in terms of the radiation attenuation parameters (RAPs) and radiographic properties of water at low and high energies (3). These properties play a vital role in the field of non-destructive test of medical samples (nuclear medicine and radiology), agricultural 
(characterization of various types of woods and mapping inhomogeneities in different parts of wood), and industrial (to check for voids and insertions in the inner part of the material) interests.

Recently, several comprehensive scientific researchers have been conducted on the suitability of some species of natural mangrove wood as a result of its unique biodegradable, biocompatible, and eco-friendly characteristics ${ }^{3}$ -6). Rhizophora spp. (R. spp.) wood has been in use as a valuable and superior alternative for manufacturing wood composites such as plywood, fiberboards, particleboards, and so on (6). Subsequently, it has been discovered that it exhibits similarities in dosimetric properties with water and other standard phantom materials at photon energies between 16.59 and $25.26 \mathrm{keV}(3,4,6)$. Consequently, it can be made as an attractive quality materials for different purposes such as diagnostic radiology, nuclear medicine, and other medical applications. Various bio-based and petroleum-based adhesives as widely investigated, have been proffered for $R$. spp. particleboards but with certain disadvantages i.e. stability, firmness, etc. (4-6). Due to some demerits from petroleumbased adhesive, the development of readily available particleboard phantoms from renewable resources will still be desirable (7).

Moreover, when $R$. spp. composites is reinforced with bio-based adhesive (SPC - Soy protein concentrate), provides outrageous advantages that include flexibility, costeffectiveness, non-toxicity, conformability, etc., and reduces attendant deleterious environmental effects (6-8). In spite of this, producing SPC-based particleboards with superior performances in larger quantities remains the main challenge to be addressed on a global scale due to its poor mechanical properties and hydrophilic nature $(8,9)$. To enhance these qualities, significant numbers of research has been conducted to modify its molecular structure through chemical crosslinking reactions $(5-7,9,10)$. It was thereafter discovered that there is an increasing demand for itaconic acid polyamidoamineepichlorohydrin (IA-PAE)/NaOH-based material because of its readily biodegradable and biocompatible nature (7-11). Therefore, in this study, different concentrations of IA-PAE with $\mathrm{NaOH}$ were incorporated into SPC/R. $s p p$. with the desire to examine the radiation dosimetric properties which was affected by different sizes of particles.

The present study is a significant one since there is no notable research that has been performed to optimize the properties of $R$. spp. phantoms developed at three different sizes of particles using SPC/NaOH/IA-PAE bio-based adhesive, which is a suitable tissue- and water-equivalent phantom material for both clinical and investigative aspects of radiation therapy dosimetry. The importance of TEPM development is to contribute to the construction of high-quality particleboard phantoms, with comparable dosimetric characteristics to water and other commercial TEPMs, and to avoid the detectable amounts of formaldehyde emissions and other volatile organic compounds using realistic, durable, and inexpensive bio-based materials. This phantom formulation will be useful in the dosimetry of medical health applications.

\section{MATERIALS AND METHODS}

\section{Preparation of bio-adhesives}

The technique for preparing and synthesizing IA-PAE resin was established in a study previously reported by Samson et al. (6) with the characteristics of the resulting product which includes $\mathrm{pH} 6.68$, solid content of $55.96 \pm$ $0.01 \mathrm{wt} \%$, and viscosity of $100.40 \pm 0.25 \mathrm{mPa}$.s. The SPC-based adhesives were prepared at $25^{\circ} \mathrm{C}$ by dissolving SPC (30 g) under constant stirring in distilled water $(70,65,60$, and $55 \mathrm{~g})$ at 600 rpm for $30 \mathrm{~min}$ in accordance with the procedure described by Zhang et al. (9). Subsequently, different concentrations of IA-PAE $(0,5,10$, and 15 wt $\%)$ were added to the SPC dispersions and vigorously stirred for $30 \mathrm{~min}$. The result of SPC/IA-PAE slurry mixture was maintained for $1 \mathrm{~h}$ at $\mathrm{pH} 11.0$ with $2 \mathrm{~N} \mathrm{NaOH}(10$ wt \%) solution.

Int. J. Radiat. Res., Vol. 19 No. 4, October 2021 
Fabrication of SPC/NaOH/IA-PAE/R. spp. particleboard phantoms

The grinding and segregation of R. spp. wood was achieved based on a previous technique detailed by Samson et al. (6). Using an iron-coated cylindrical mould $\left(27 \times 0.5 \mathrm{~cm}^{2}\right)$, the adhesive sample formulations were thoroughly mixed with different R. spp. particle sizes and was subsequently cold-compressed at $5 \mathrm{kgcm}^{-2}, 3$ $\min$, and $20^{\circ} \mathrm{C}$. The samples were thereafter hot-pressed into particleboards with pressing pressure of $180 \mathrm{kgcm}^{-2}$ and was held for $15 \mathrm{~min}$ at $170^{\circ} \mathrm{C}{ }^{(6)}$. Just after the mould was released, the phantom sections were smoothed to the desired dimensions and conditioned for two weeks at 20 ? with relative humidity of $65 \%$. All the measured particleboards were performed in five replicates for each particle size at different concentrations of IA-PAE adhesive, making a total of 75 particleboards manufactured as coded in table 1 . The physical, mechanical, and dimensional stability (PMDS) tests were conducted according to JIS A 5908:2003 (12) as well as the technique proposed by Samson et al. (6).

Table 1. Comparison of densities of SPC-based R. spp. plug phantoms.

\begin{tabular}{|c|c|c|}
\hline Particle size $(\boldsymbol{\mu m})$ & Plug phantoms & Average density $\left(\mathrm{g} / \mathrm{cm}^{\mathbf{3}}\right)$ \\
\hline \multirow{4}{*}{$149-500$} & $\mathrm{~A}_{0}$ & $1.021 \pm 0.026$ \\
\cline { 2 - 3 } & $\mathrm{A}_{1}$ & $1.085 \pm 0.007$ \\
\cline { 2 - 3 } & $\mathrm{A}_{5}$ & $0.979 \pm 0.016$ \\
\cline { 2 - 3 } & $\mathrm{A}_{10}$ & $0.997 \pm 0.010$ \\
\cline { 2 - 3 } & $\mathrm{A}_{15}$ & $1.010 \pm 0.003$ \\
\hline \multirow{4}{*}{$74-149$} & $\mathrm{~B}_{0}$ & $1.025 \pm 0.032$ \\
\cline { 2 - 3 } & $\mathrm{B}_{1}$ & $1.030 \pm 0.015$ \\
\cline { 2 - 3 } & $\mathrm{B}_{5}$ & $1.034 \pm 0.005$ \\
\cline { 2 - 3 } & $\mathrm{B}_{10}$ & $0.994 \pm 0.014$ \\
\cline { 2 - 3 } & $\mathrm{B}_{15}$ & $1.009 \pm 0.003$ \\
\hline \multirow{7}{*}{$\leq 74$} & $\mathrm{C}_{0}$ & $1.097 \pm 0.027$ \\
\cline { 2 - 3 } & $\mathrm{C}_{1}$ & $1.067 \pm 0.003$ \\
\cline { 2 - 3 } & $\mathrm{C}_{5}$ & $1.032 \pm 0.011$ \\
\cline { 2 - 3 } & $\mathrm{C}_{10}$ & $0.961 \pm 0.012$ \\
\cline { 2 - 3 } & $\mathrm{C}_{15}$ & $1.005 \pm 0.002$ \\
\hline
\end{tabular}

\section{Plug phantoms measurements for computed tomography (CT) scan}

The preparation of SPC-based R. spp. plug phantoms compatible with CT electron density phantom (062M, CIRS, Norfolk, USA) was performed through moulding on top of a cylindrical base, $3 \mathrm{~cm}$ in diameter and $7 \mathrm{~cm}$ in length and was glued vertically into a stack using polyvinyl acetate adhesive. Each sample plug phantom was subsequently trimmed and oriented (figure 1). The results of the selected plug phantoms are listed in table 1.

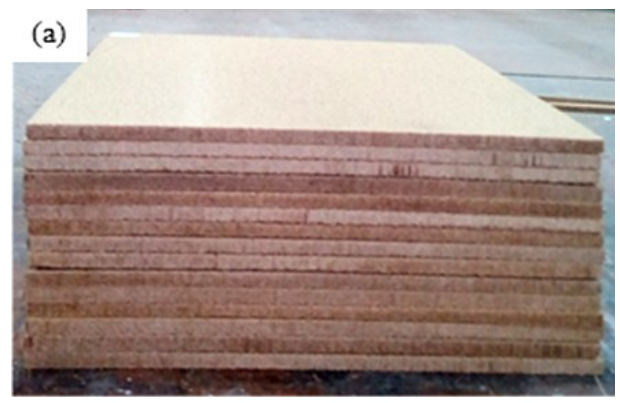

(b)

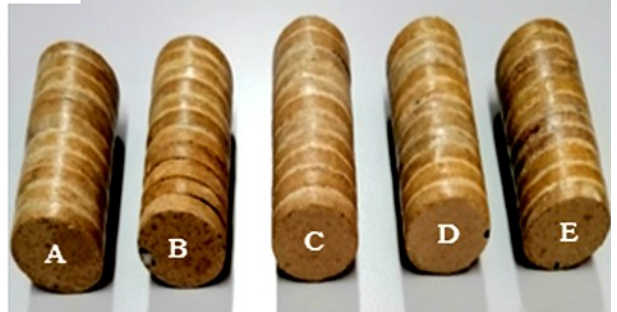

Figure 1. (a) Fabricated particleboards and (b) sample plug phantoms. A, B, C, D, and E refers to binderless, $0,5,10$, and 15 wt\% IA-PAE.

\section{Characterization of SPC/NaOH/IA-PAE/R. spp. particleboard phantoms} Thermogravimetric (TG) analysis

TG measurement was carried out on a TG analyser (TGA-7, Norwalk, USA). The average sample size was $5 \mathrm{mg}$ and the nitrogen flow-rate was $20 \mathrm{mLmin}^{-1}$. The temperature range for scanning was from $30-900^{\circ} \mathrm{C}$ at $10^{\circ} \mathrm{Cmin}^{-1}$ increment, which was held for $5 \mathrm{~min}$ at $900^{\circ} \mathrm{C}$.

\section{Fourier transform infrared spectroscopy analysis}

(FTIR)

FTIR spectra for SPC-based R. spp. adhesives were obtained from IRPrestige-21 Shimadzu FTIR spectrometer by diffused reflectance. The samples were prepared by adding about $1 \mathrm{mg}$ of each dried adhesive sample to $100 \mathrm{mg}$ of $\mathrm{KBr}$ crystals and compressed at $32 \mathrm{MPa}$ for $3 \mathrm{~min}$ to a thickness of $0.5 \mathrm{~mm}$ and diameter of 12.71 $\mathrm{mm}$. Measurements were carried out by 
employing 32 scans with a resolution of $4 \mathrm{~cm}^{-1}$, at a spectral wavenumber range of $4000-400$ $\mathrm{cm}^{-1}$.

\section{Microstructure and energy dispersive $X$-ray analysis}

Samples of size $\left(0.5 \times 0.5 \times 0.5 \mathrm{~cm}^{3}\right)$ were mounted on a metal strap holder which were dried in an oven at $120^{\circ} \mathrm{C}$, and then gold-coated for imaging at $45 \mathrm{~mA}$ for 30 seconds. Images of the coated specimens were observed on the field emission scanning electron microscope (FEI Quanta FEG-650, Netherlands) using $20 \mathrm{kV}$ at $30^{\circ}$ with magnifications of $1000 \times$. Analyses were performed under vacuum conditions. The effective atomic number ( $\mathrm{Z}_{\mathrm{eff}}$ ) and electron fraction $\left(\alpha_{i}\right)$ of the samples were determined using Equation $1(6,13)$.

$$
\begin{aligned}
& Z_{a f f}=\frac{\sigma_{a}}{\sigma_{e}}=\left[\sum_{i}^{r} \alpha_{i} z_{i}{ }^{m}\right]^{1 / m}=\left[\sum_{i}^{r} \frac{N_{g}^{i}}{N_{g}} z_{i}{ }^{m}\right]^{1 / m}= \\
& {\left[\sum_{i}^{r} \frac{\omega_{i} z_{i} / A_{i}}{\sum_{i}\left(\omega_{i} z_{i} / A_{i}\right)} z_{i}^{m}\right]^{1 / m}}
\end{aligned}
$$

where, $\sigma_{a}, \sigma_{a}, Z_{i}, \alpha_{i}, A_{i}$, and $\omega_{i}$ are the atomic cross-section, electronic cross-section, atomic number, electron fraction, effective atomic weight, and fractional weight of $i^{\text {th }}$ element $(i=1,2,3, . ., r)$ in the sample materials, while $\mathrm{m}$ is the experimental coefficient for biological materials and water with a value of 3.4 (13).

\section{$X$-ray diffraction (XRD) analysis}

The crystallinity of the samples was investigated by utilizing a Bruker D8 Advance $\mathrm{X}$-ray diffractometer operating with $\mathrm{Cu}-\mathrm{K} \alpha 1$ $\mathrm{X}$-ray radiation of $1.5406 \AA$ at $40 \mathrm{kV}_{\mathrm{p}}$ and $40 \mathrm{~mA}$, using a cobalt source detector and a $2 \theta$ scan ranging from $5^{\circ}-80^{\circ}$ at $2^{\circ} / \mathrm{min}$. Structural analysis of the XRD data was performed via EVA $5+$ software. The determination of the index of crystallinity was achieved by equation 2 (6).

$C_{r} I(\%)=\left[\frac{I_{200}-I_{a m}}{I_{200}}\right] \times 100$

where, $I_{200}$ and $I_{\mathrm{am}}$ are the peak intensities

\section{4}

corresponding to crystalline and amorphous fractions.

\section{Particleboards evaluation RAPS}

The photon attenuation measurements were performed using a LEGe detector system combined with a multichannel analyzer (MCA-3 series), high voltage source with positive polarity, absorber particleboard samples, a radioactive point source, and $\mathrm{Pb}$ collimator. The detector had an energy resolution of $400 \mathrm{eV}$ for $59.54 \mathrm{keV}$ photons from ${ }^{241} \mathrm{Am}$ with an active crystal area of $2 \mathrm{~cm}^{2}$ and a diameter of $1.6 \mathrm{~cm}$, kept at liquid nitrogen temperature $\left(-196^{\circ} \mathrm{C}\right)$. Both distances from the samples to the metal plate and the detector were $7 \mathrm{~cm}$ and $8.9 \mathrm{~cm}$, while the diameter of the $\mathrm{Pb}$ collimator was 0.3 $\mathrm{cm}$. Particleboard samples were prepared and irradiated according to the technique proposed by Samson et al. (6). The mass attenuation coefficient $\left(\mu_{m}\right)$ being a function of only energy and the atomic number of the material is calculated using equation 3 :

$\mu_{m}=\frac{1}{x \cdot \rho} \ln \left(\frac{I_{o}}{I}\right)$

where, $I$ and $I_{0}$ are the number of counts under the photons peak with and without samples. $x$ and $\rho$ are the physical thickness and density. In the case of a compound, the $\mu_{m}$ of any composite material consisting of several mixture of chemical elements present in the sample is measured as given in equation 4 :

$\mu_{m}=\left(\frac{\mu}{\rho}\right)_{\text {composite }}=\omega_{1}\left(\frac{\mu}{\rho}\right)_{1}+\omega_{2}\left(\frac{\mu}{\rho}\right)_{2}+\cdots=\sum_{i=1}^{N} \omega_{i}\left(\frac{\mu}{\rho}\right)_{i}$

where, $\omega_{i}$ and $(\mu / \rho)_{i}$ denote the weight fraction and $\mu_{m}$ of the constituent elements $i^{\text {th }}$.

The half-value layer (HVL) is the thickness of a specified material used in dividing the photon intensity and assess the capacity of radiation attenuation for any material, equation 5 provides the expression for the HVL value ${ }^{(1,14)}$.

$H V L\left(X_{1 / 2}\right)=\frac{\ln 2}{\left(\mu_{m} \times \rho\right)}$

The mean free path (MFP) provides an Int. J. Radiat. Res., Vol. 19 No. 4, October 2021 
approximation of the average distance travelled by the photon in the sample material before it can be absorbed or scattered (14). It can be calculated as shown in equation 6:

$\operatorname{MFP}(\lambda)=\frac{1}{\left(\mu_{m} \times \rho\right)}$

Equation 7 is used for the calculation of associated standard error in the experimental $\mu_{m}$ values.

$\frac{\Delta \mu_{m}}{\mu_{m}}=\sqrt{\left(\frac{\Delta I_{o}}{I_{0} \mu x \rho}\right)^{2}+\left(\frac{\Delta I}{I_{\mu x \rho}}\right)^{2}+\left(\frac{\Delta x \cdot \rho}{x \cdot \rho}\right)^{2}}$

where, the first, second, and third term denotes the statistical fluctuation intensities of the transmitted and incident photon beam and its uncertainty in measuring sample mass-thickness. All data were statistically analyzed using SPSS V22.0 and the results was compared with the calculated values of water (XCOM) (15).

\section{Measurement of CT numbers, electron densities (ED) and density distribution profiles (DDPs)}

CT scan was performed at three X-ray CT tube voltages $(80,120$, and $135 \mathrm{kVp})$, current at $250 \mathrm{mAs}$, in-plane resolution of $0.714 \times 0.714$ $\mathrm{mm}^{2} /$ pixel, and slice thickness of $1 \mathrm{~mm}$ using Somatom Definition. AS+ scanner. Slice acquisition times were 4 seconds per scan and $365.625 \mathrm{~mm}$ field of reconstruction was captured in a 512 pixel $\times 512$ pixel image. The CT number was measured using equation 8 (16).

CT number $=K\left(\frac{\mu-\mu_{w}}{\mu_{w}}\right)$

where, $\mu$ and $\mu_{w}$ are the linear attenuation coefficients of the sample and water, and $K$ is the magnification contrast with the value of 1000 . The discrepancy in each scanned sample from the computed value of water was calculated using the Chi-square $\left(x^{2}\right)$ goodness of fit test shown in equation 9:

$\chi^{2}=\sum_{i=1}^{N}\left(\frac{\mathrm{CT}_{w_{i}}-f\left(\mathrm{CT}_{i}\right)}{\sigma_{i}}\right)^{2}$ where, $\mathrm{CT}_{w i}$ and $\mathrm{CT}_{i}$ are the $\mathrm{CT}$ number of water and sample, and $\sigma$ is the uncertainty in the sample plug phantoms. A couple of standard TEMs with known densities were scanned as presented in figure 2 , since CT numbers varies among scanners from different manufacturers, to establish the linear correlation of the calibration curve.

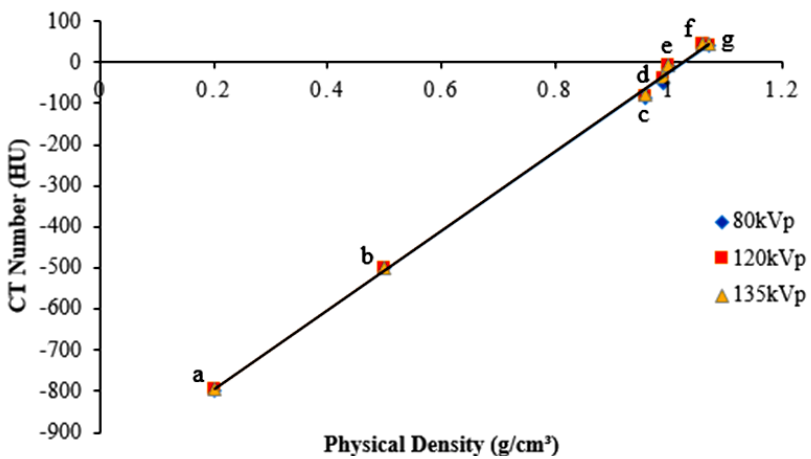

Figure 2. Calibration curve between CT numbers and physical densities. (a) lung (inhale), (b) lung (exhale), (c) adipose, (d) breast (50/50), (e) water, (f) muscle, and (g) liver. (Error bars cannot be seen because they are smaller than the symbols).

\section{RESULTS}

\section{TG properties}

The thermal stability study showed that TG and DTG techniques permitted the specification of the temperature range, whereby the samples were thermally stable within $0^{\circ} \mathrm{C}-280.67^{\circ} \mathrm{C}$ (figure 3). The ratio of weight loss was found to be within $4.51-11.66 \%$ at the first peak, while the second region was initiated in the range between $71.48-87.57 \%$ (figure 3(a)). These stages were assigned to the evaporation of residual moisture, degradation of the main skeleton structure, and disruption of the quaternary structure accompanied by partial protein denaturation, which is involved with the thermal breakage of $\mathrm{C}-\mathrm{C}, \mathrm{C}-\mathrm{N}$, and $\mathrm{C}-\mathrm{O}$ bonds $(6,17)$. SPC pyrolysis was seen to peak between $180-400^{\circ} \mathrm{C}$, while the DTG curve appears to be range of $400-900^{\circ} \mathrm{C}$ (figure (3b)). These findings confirm an improvement in the thermal stability following $\mathrm{NaOH} / \mathrm{IA}-\mathrm{PAE}$ incorporation that suggest the presence of a chemical cross-linking reaction. 

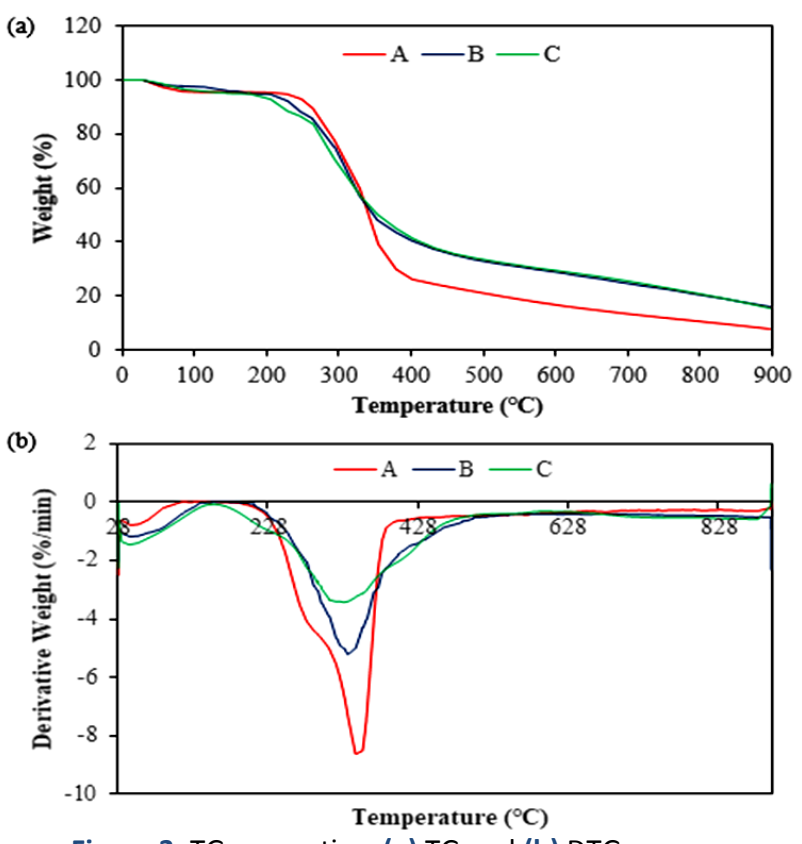

Figure 3. TG properties: (a) TG and (b) DTG curves. ABinderless R. spp., BSPC/R. spp., and CSPC/NaOH/IA-PAE/R. spp.

\section{FTIR analysis}

The characteristic broad absorption peaks were observed at 3000-3442.94 $\mathrm{cm}^{-1}$, which are attributable to the free and bonded $\mathrm{O}-\mathrm{H}$ and $\mathrm{N}-\mathrm{H}$ groups (figure 4). The bands relating to $\mathrm{C}=0$ stretching $\quad\left(1658.78 \quad \mathrm{~cm}^{-1}\right), \quad \mathrm{N}-\mathrm{H}$ bending (1575.84 $\mathrm{cm}^{-1}$ ), C-N stretching/N-H bending vibrations (1317.38-1259.52 $\left.\mathrm{cm}^{-1}\right)$ were ascribed to amide I, amide II, and amide III (6). In addition, the bands at 1157.29, 1504.48, 1456.26, 1051.20, and 2376.30-2341.58 $\mathrm{cm}^{-1}$ were assigned to ester $\mathrm{C}-\mathrm{O}$ moieties, $\mathrm{C}-\mathrm{H}$ deformation of aliphatic, skeletal vibration of $\mathrm{C}=\mathrm{C}$, stretching vibration of $\mathrm{COO}-/ \mathrm{C}-\mathrm{O}$, and amino hydrohalides $(11,17)$.

\section{Microscopy images}

Figure 5(a) exhibits the stacks of the binderless R. spp., showing some number of gaps and voids in the composites, which could weaken the bonding between fiber and matrix (3). In figure 5(b) it is visible that some agglomeration occurred in the composite particleboards. This is due to the poor interfacial adhesion with the matrix, thus the composite toughness was increased. Figure 5(c-d) depicts that the $\mathrm{NaOH} / \mathrm{IA}-\mathrm{PAE}$ (15 wt\%) distorted the void spaces, align uneven fibers, and bring

about compact fracture surfaces within the particleboards $(9,10)$. The computed $Z_{\text {eff }}$ values for the selected samples lies within the range of 7.157.59 (table 2).

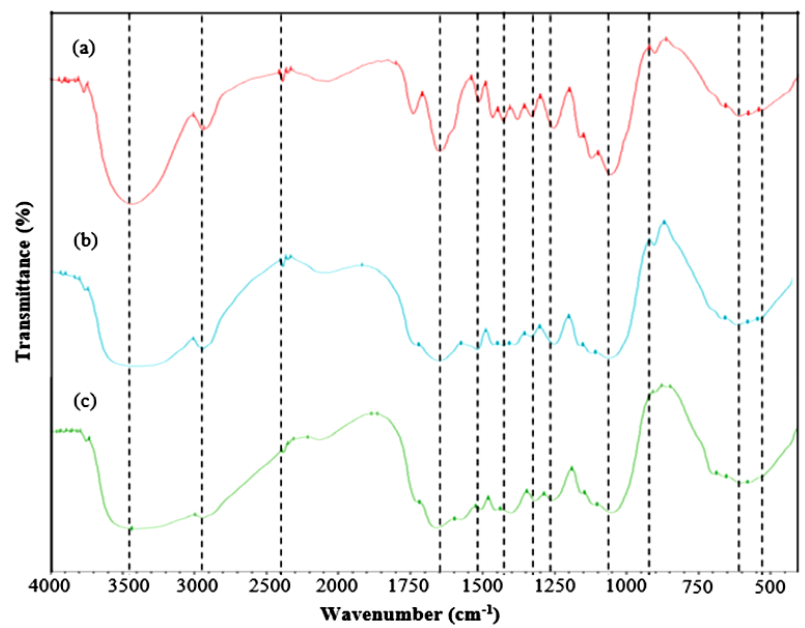

Figure 4. FTIR spectra: (a) Binderless R. spp., (b) SPC/R. spp., and (c) SPC/NaOH/IA-PAE/R. spp.
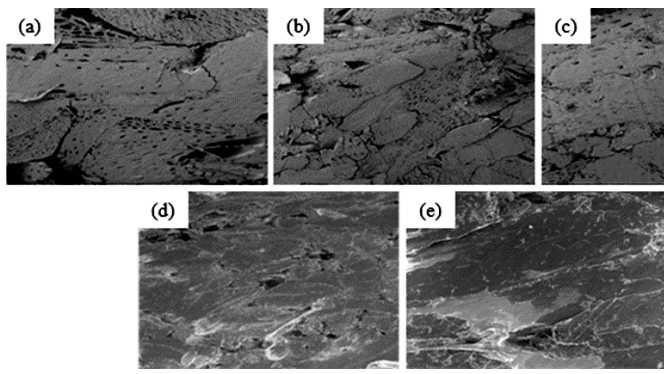

Figure 5. SEM images: (a) Binderless R. spp., (b) untreated SPC/R. spp., (c) SPC/NaOH/IA-PAE/R. spp. (5 wt\%), (d) SPC/ $\mathrm{NaOH} / \mathrm{IA}-\mathrm{PAE} / \mathrm{R}$. spp. (10 wt\%), and (e) SPC/NaOH/IA-PAE/R. spp. (15 wt\%).

\section{Structural Properties}

The results of the XRD measurement are displayed in figure 6 . The diffraction patterns observed at $2 \theta$ with the d-spacing were estimated at $14.28^{\circ}(6.165 \AA), 22.41^{\circ}$ (3.998 $\AA$ ), and $34.75^{\circ}(2.582 \AA)$ for SPC/NaOH/IA-PAE $/ R$. spp., $57.4^{3} \int^{\circ}\left({ }^{0} .049 \AA\right), 66.6^{3} \circ\left(7 .{ }^{3} 97 \AA\right), 78.8^{2} \circ$ $(2.600 \AA)$ for $\mathrm{SPC} / \mathrm{NaOH} /$ R. spp., $13.73^{\circ}(6.405$ $\AA)$ ), $22.12^{\circ}(3.954 \AA), 34.52^{\circ}(2.596 \AA$ ) for SPC $/ R$. spp., and $58 . .^{01} \circ\left({ }^{0} .475 \AA\right), 66.7^{1 \circ}\left(7 .^{30} 4 \AA\right)$, and $34.52^{\circ}(2.595 \AA)$ for binderless $R$. spp., particleboards, matched to the (101), (002), and (004) planes. The overall results for the crystallinity index are $42.27 \%, 32.12 \%, 27.98 \%$, and $41.58 \%$, respectively.

Int. J. Radiat. Res., Vol. 19 No. 4, October 2021 
Table 2. Elemental contents and $Z_{\text {eff }}$ values.

\begin{tabular}{|c|c|c|c|c|c|c|c|c|c|c|c|c|c|}
\hline \multirow{2}{*}{ Sample } & \multicolumn{12}{|c|}{ Elemental composition (\%) } & \multirow{2}{*}{$Z_{\text {eff }}$} \\
\hline & $\mathbf{H}$ & C & $\mathbf{N}$ & 0 & $\mathrm{Na}$ & $\mathrm{Mg}$ & $\mathbf{P}$ & S & $\mathrm{Cl}$ & K & $\mathrm{Ca}$ & Zn & \\
\hline Water & 11.11 & - & - & 88.89 & - & - & - & - & - & - & - & - & $7.50^{\mathrm{a}}$ \\
\hline Perspex & 31.97 & 59.98 & - & 8.05 & - & - & - & - & - & - & - & - & $5.21^{\mathrm{a}}$ \\
\hline $\mathrm{C}_{0}$ & - & 49.04 & 1.80 & 48.92 & - & - & - & 0.24 & - & - & - & - & $7.15^{b}$ \\
\hline $\mathrm{C}_{1}$ & - & 49.33 & 4.42 & 45.21 & 0.34 & - & - & - & 0.32 & 0.16 & 0.22 & - & $7.40^{b}$ \\
\hline$C_{5}$ & - & 47.96 & 5.17 & 45.81 & 0.33 & 0.09 & - & - & 0.41 & 0.09 & 0.14 & - & $7.41^{b}$ \\
\hline$C_{10}$ & - & 51.24 & 4.54 & 43.04 & 0.22 & - & 0.10 & 0.10 & 0.35 & 0.20 & 0.17 & - & $7.45^{b}$ \\
\hline$C_{15}$ & - & 49.73 & 4.88 & 44.35 & 0.25 & 0.10 & - & - & 0.27 & 0.25 & 0.15 & 0.02 & $7.59^{b}$ \\
\hline Almond gum & 6.03 & 41.72 & 0.27 & 51.98 & - & - & - & - & - & - & - & - & $7.15^{\mathrm{c}}$ \\
\hline
\end{tabular}

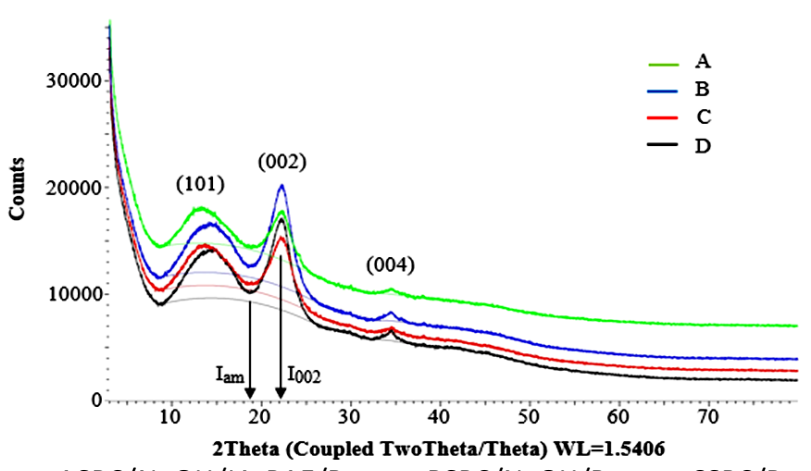

Figure 6. Indexed XRD patterns: ASPC/NaOH/IA-PAE/R. spp., BSPC/NaOH/R. spp., CSPC/R. spp., and DBinderless R. spp. particleboards.

The results show remarkable values of MC and SC, ranging from $6.5 \pm 0.2-8.4 \pm 0.3 \%$ and $29.5 \pm 0.2-39.1 \pm 0.9 \%$ (table 3 ). The maxima modulus of rupture (MOR) and elasticity (MOE), and internal bonding (IB) values were $\leq 74 \mu \mathrm{m}$, while the minima values appear at 74-149 $\mu \mathrm{m}$ and $149-500 \mu \mathrm{m}$. Meanwhile, samples of about
$15 \mathrm{wt} \%$ of IA-PAE at $\leq 74 \mu \mathrm{m}$ exhibited a decrease in water absorption (WA) and thickness swelling (TS) ratio (12). On the other hand, the higher WA and TS observed with 0,5 , and $10 \mathrm{wt} \%$ of IA-PAE, might be due to the elimination of hydrophobic substances, which promote water penetration and retention $(6,7)$.

Table 3. Comparison of PMDS properties.

\begin{tabular}{|c|c|c|c|c|c|c|c|c|}
\hline Particle size $(\mu \mathrm{m})$ & Sample & MC (\%) & SC (\%) & IB (MPa) & MOR (MPa) & MOE (GPa) & WA (\%) & TS (\%) \\
\hline \multirow{5}{*}{ 149-500 } & $A_{0}$ & $7.9 \pm 0.2$ & $29.5 \pm 0.2$ & $0.08 \pm 0.01$ & $2.3 \pm 0.14$ & $0.34 \pm 0.09$ & $87.4 \pm 0.2$ & $69.9 \pm 0.3$ \\
\hline & $A_{1}$ & $7.2 \pm 0.4$ & $31.7 \pm 0.7$ & $0.15 \pm 0.02$ & $3.3 \pm 0.16$ & $0.98 \pm 0.05$ & $79.5 \pm 0.5$ & $66.4 \pm 0.2$ \\
\hline & $A_{5}$ & $7.9 \pm 0.1$ & $32.9 \pm 0.3$ & $0.31 \pm 0.02$ & $10.5 \pm 0.23$ & $1.12 \pm 0.09$ & $44.3 \pm 0.1$ & $55.4 \pm 0.1$ \\
\hline & $A_{10}$ & $6.8 \pm 0.1$ & $33.0 \pm 0.2$ & $0.39 \pm 0.08$ & $11.8 \pm 0.07$ & $2.29 \pm 0.03$ & $33.7 \pm 0.5$ & $48.5 \pm 0.3$ \\
\hline & $A_{15}$ & $8.2 \pm 0.4$ & $34.9 \pm 0.4$ & $0.42 \pm 0.05$ & $13.1 \pm 0.39$ & $3.99 \pm 0.07$ & $32.5 \pm 0.6$ & $36.9 \pm 0.1$ \\
\hline \multirow{5}{*}{ 74-149 } & $\mathrm{B}_{0}$ & $6.9 \pm 0.4$ & $30.9 \pm 0.1$ & $0.09 \pm 0.02$ & $3.9 \pm 0.07$ & $0.47 \pm 0.09$ & $77.1 \pm 0.4$ & $66.3 \pm 0.2$ \\
\hline & $\mathrm{B}_{1}$ & $6.5 \pm 0.2$ & $33.0 \pm 0.4$ & $0.11 \pm 0.08$ & $5.5 \pm 0.15$ & $1.15 \pm 0.27$ & $72.8 \pm 0.1$ & $62.9 \pm 0.1$ \\
\hline & $\mathrm{B}_{5}$ & $7.9 \pm 0.3$ & $33.2 \pm 0.4$ & $0.30 \pm 0.03$ & $10.4 \pm 0.10$ & $2.56 \pm 0.86$ & $52.5 \pm 0.2$ & $45.4 \pm 0.1$ \\
\hline & $\mathrm{B}_{10}$ & $6.7 \pm 0.2$ & $34.7 \pm 0.2$ & $0.44 \pm 0.09$ & $13.5 \pm 0.08$ & $5.25 \pm 0.22$ & $47.5 \pm 0.1$ & $31.4 \pm 0.3$ \\
\hline & $\mathrm{B}_{15}$ & $6.8 \pm 0.2$ & $35.7 \pm 0.6$ & $0.48 \pm 0.02$ & $16.2 \pm 0.17$ & $6.05 \pm 0.78$ & $45.9 \pm 0.2$ & $28.1 \pm 0.2$ \\
\hline \multirow{5}{*}{$\leq 74$} & $\mathrm{C}_{0}$ & $7.5 \pm 0.7$ & $32.6 \pm 0.4$ & $0.08 \pm 0.06$ & $3.9 \pm 0.74$ & $1.35 \pm 0.17$ & $71.1 \pm 0.4$ & $60.1 \pm 0.9$ \\
\hline & $\mathrm{C}_{1}$ & $8.4 \pm 0.3$ & $31.1 \pm 0.9$ & $0.28 \pm 0.04$ & $4.0 \pm 0.60$ & $1.81 \pm 0.33$ & $52.1 \pm 0.2$ & $59.5 \pm 0.9$ \\
\hline & $\mathrm{C}_{5}$ & $8.2 \pm 0.2$ & $34.6 \pm 0.2$ & $0.52 \pm 0.01$ & $10.8 \pm 0.37$ & $4.40 \pm 1.03$ & $26.6 \pm 0.6$ & $22.3 \pm 0.6$ \\
\hline & $C_{10}$ & $7.5 \pm 0.3$ & $36.2 \pm 0.1$ & $0.54 \pm 0.02$ & $14.2 \pm 0.23$ & $6.28 \pm 1.15$ & $19.6 \pm 0.3$ & $14.9 \pm 0.9$ \\
\hline & $\mathrm{C}_{15}$ & $7.2 \pm 0.6$ & $39.1 \pm 0.9$ & $0.56 \pm 0.01$ & $18.4 \pm 0.28$ & $7.58 \pm 1.83$ & $18.1 \pm 0.9$ & $11.1 \pm 0.7$ \\
\hline
\end{tabular}

Int. J. Radiat. Res., Vol. 19 No. 4, October 2021 


\section{Evaluation of RAPs}

From figure 7, the variation of $\mu_{m}$ values with that of water (XCOM) have similar characteristics for the photon energies at the three selected particle sizes, which satisfactorily matches the results of previous studies ${ }^{(3,6)}$. As the sample particle sizes decrease and IA-PAE increases, the $\mu_{m}$ values vary from 1.12-0.39 $\mathrm{cm}^{2} \mathrm{~g}^{-1}$. Samples $\mathrm{A}_{15}, \mathrm{~B}_{15}, \mathrm{C}_{10}$, and $\mathrm{C}_{15}$ with $\mathrm{p}$-values of $0.054,0.055,0.060$, and 0.075 show no significant difference to that of water as presented in table 4 . Therefore, it can easily be seen that HVL and MFP values are minima at lower energies and increases with an increase in photon energy (figures 8 and 9).
These results indicated that samples $\mathrm{A}_{15}, \mathrm{~B}_{15}, \mathrm{C}_{10}$, and $\mathrm{C}_{15}$ can provide appropriate features as suitable TEPMs.

\section{Evaluation of CT numbers, ED, and DDPs}

From table $5, \mathrm{C}_{15}$ has the closest mean CT numbers and ED values, as well as DDPs (figure $10)$ to water. This is closely followed by $B_{15}, A_{15}$, and $\mathrm{C}_{10}$ at the three X-ray CT tube voltages depicted by the $x^{2}$ values (table 6), which revealed the nearest value of $\mathrm{C}_{15}$ to water with insignificant difference.
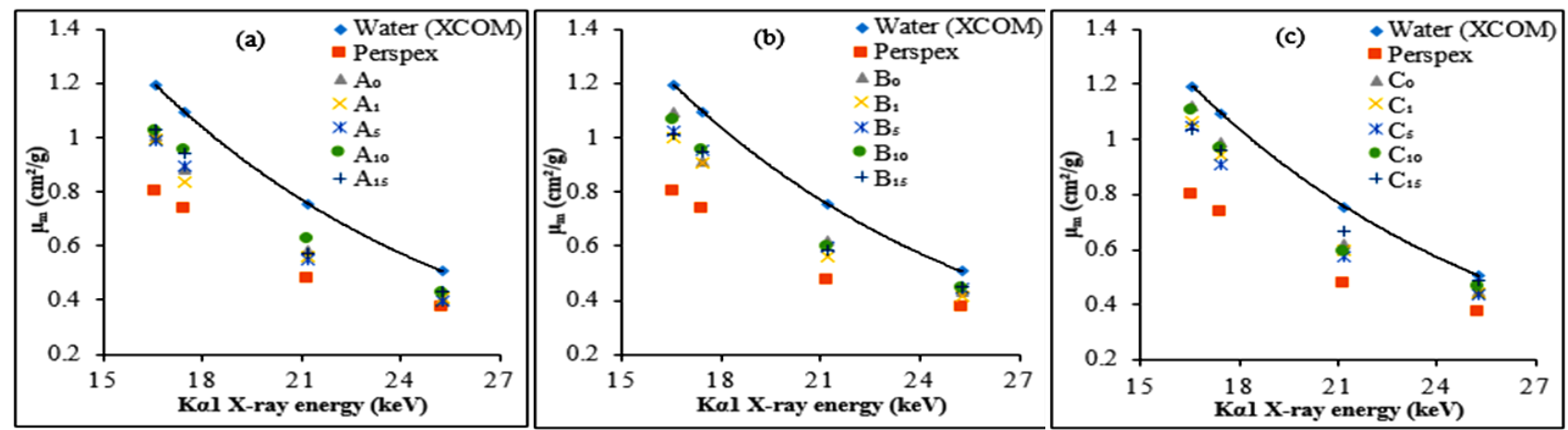

Figure 7. Variation of: (a) 149500, (b) 74149, and (c) $74 \mu \mathrm{m}$. (Error bars cannot be seen because they are smaller than the symbols).
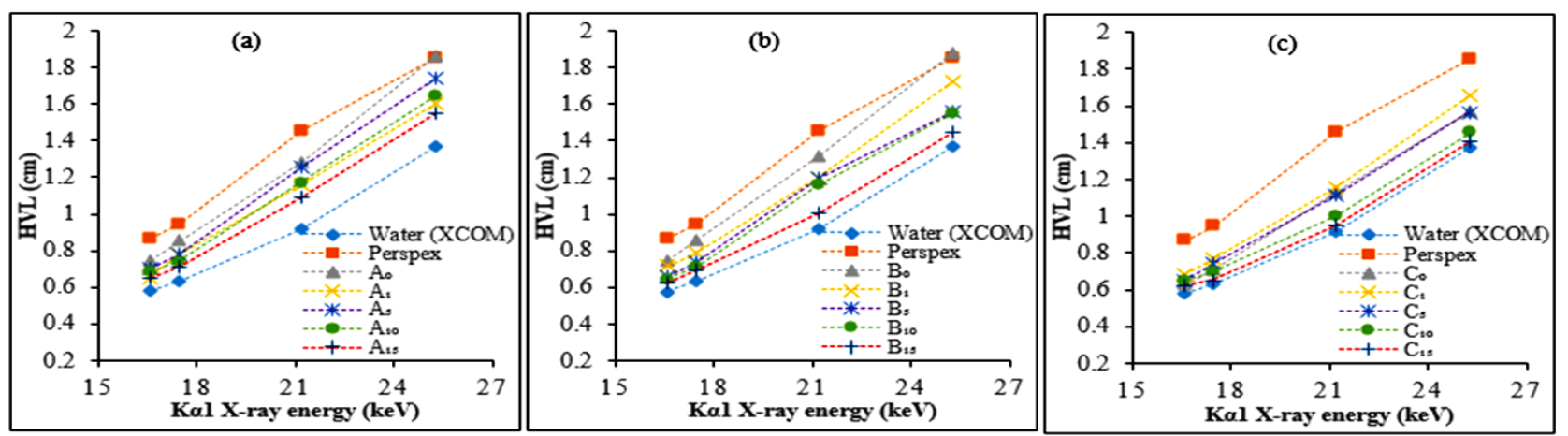

Figure 8. HVL: (a) 149500, (b) 74149, and (c) $74 \mu \mathrm{m}$. (Error bars cannot be seen because they are smaller than the symbols).
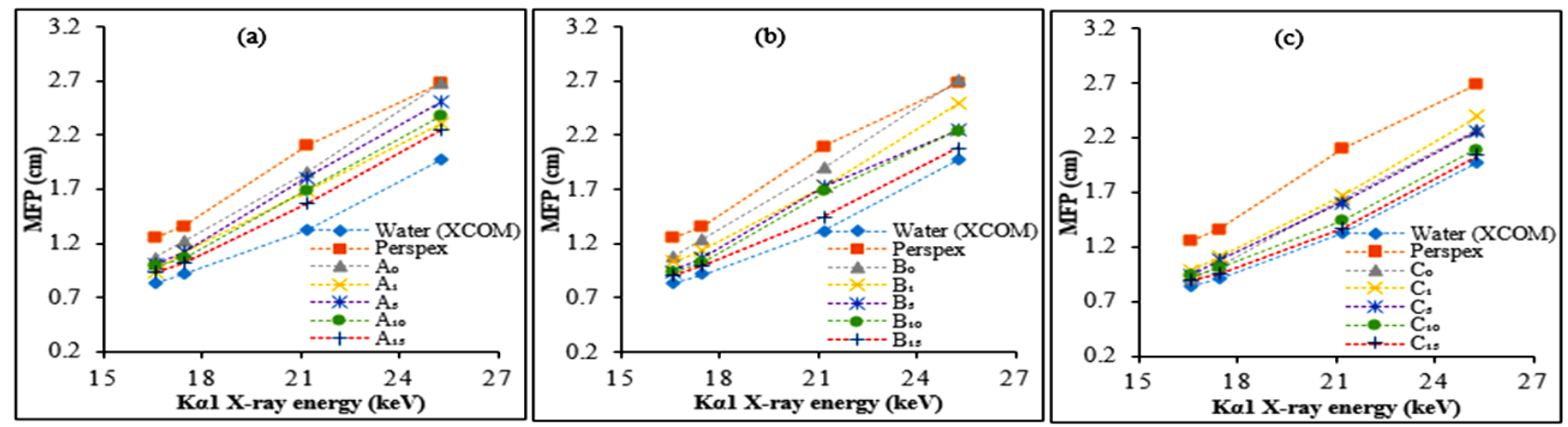

Figure 9. MFP: (a) 149500, (b) 74149, and (c) $74 \mu \mathrm{m}$. (Error bars cannot be seen because they are smaller than the symbols). 
Table 4. Paired t-test of the of particleboard phantoms compared to water (XCOM).

\begin{tabular}{|c|c|c|c|c|c|c|c|c|}
\hline \multirow{3}{*}{ Pair } & \multicolumn{5}{|c|}{ Paired Differences } & \multirow{3}{*}{$\mathrm{t}$} & \multirow{3}{*}{$d f$} & \multirow{3}{*}{$\begin{array}{c}\text { Sig. } \\
\text { (2-tailed) }\end{array}$} \\
\hline & \multirow[t]{2}{*}{ Mean (d) } & \multirow[t]{2}{*}{ Std. Dev. $\left(\sigma_{d}\right)$} & \multirow{2}{*}{$\begin{array}{l}\text { Std. Error } \\
\text { Mean }\end{array}$} & \multicolumn{2}{|c|}{$\begin{array}{c}\text { 95\% Confidence Interval of the } \\
\text { difference }\end{array}$} & & & \\
\hline & & & & Lower & Upper & & & \\
\hline$A_{0}$ & 0.168 & 0.047 & 0.023 & 0.0434 & 0.1921 & 5.043 & 3 & 0.015 \\
\hline$A_{1}$ & 0.185 & 0.067 & 0.034 & 0.0479 & 0.2627 & 4.600 & 3 & 0.019 \\
\hline$A_{5}$ & 0.180 & 0.049 & 0.024 & 0.0325 & 0.1875 & 4.519 & 3 & 0.020 \\
\hline$A_{10}$ & 0.130 & 0.038 & 0.019 & 0.0102 & 0.1298 & 3.723 & 3 & 0.034 \\
\hline$A_{15}$ & 0.145 & 0.048 & 0.024 & -0.0023 & 0.1513 & 3.087 & 3 & 0.054 \\
\hline $\mathrm{B}_{0}$ & 0.121 & 0.046 & 0.028 & 0.0246 & 0.1764 & 4.216 & 3 & 0.021 \\
\hline$B_{1}$ & 0.167 & 0.049 & 0.025 & 0.0373 & 0.1962 & 4.677 & 3 & 0.018 \\
\hline$B_{5}$ & 0.140 & 0.034 & 0.017 & 0.0153 & 0.1247 & 4.072 & 3 & 0.027 \\
\hline$B_{10}$ & 0.122 & 0.042 & 0.021 & 0.0054 & 0.1391 & 3.441 & 3 & 0.041 \\
\hline$B_{15}$ & 0.139 & 0.058 & 0.029 & -0.0035 & 0.1805 & 3.061 & 3 & 0.055 \\
\hline $\mathrm{C}_{0}$ & 0.095 & 0.034 & 0.017 & 0.0350 & 0.1439 & 5.229 & 3 & 0.014 \\
\hline $\mathrm{C}_{1}$ & 0.127 & 0.042 & 0.021 & 0.0107 & 0.1428 & 3.698 & 3 & 0.034 \\
\hline $\mathrm{C}_{5}$ & 0.154 & 0.053 & 0.027 & 0.0043 & 0.1743 & 3.342 & 3 & 0.044 \\
\hline $\mathrm{C}_{10}$ & 0.117 & 0.035 & 0.018 & -0.0039 & 0.1084 & 2.960 & 3 & 0.060 \\
\hline$C_{15}$ & 0.142 & 0.068 & 0.034 & -0.0169 & 0.1999 & 2.687 & 3 & 0.075 \\
\hline
\end{tabular}

Table 5. Comparison of computed CT number and ED.

\begin{tabular}{|c|c|c|c|c|c|c|c|c|c|}
\hline \multirow[b]{2}{*}{ Sample } & \multicolumn{3}{|c|}{$80 \mathrm{kVp}$} & \multicolumn{3}{|c|}{$120 \mathrm{kVp}$} & \multicolumn{3}{|c|}{$135 \mathrm{kVp}$} \\
\hline & $\begin{array}{c}\text { Average } \\
\text { CT No }\end{array}$ & $\begin{array}{c}\text { Average } \\
\text { SD }\end{array}$ & $\begin{array}{c}\text { ED } \times 10^{23} \\
\left(\text { elect } / \mathrm{cm}^{3}\right)\end{array}$ & $\begin{array}{l}\text { Average } \\
\text { CT No }\end{array}$ & $\begin{array}{c}\text { Average } \\
\text { SD }\end{array}$ & $\begin{array}{c}\text { ED } \times 10^{23} \\
\left(\text { elect } / \mathrm{cm}^{3}\right)\end{array}$ & $\begin{array}{l}\text { Average } \\
\text { CT No }\end{array}$ & $\begin{array}{c}\text { Average } \\
\text { SD }\end{array}$ & $\begin{array}{c}\text { ED } \times 10^{23} \\
\left(\text { elect } / \mathrm{cm}^{3}\right)\end{array}$ \\
\hline$A_{0}$ & 84.334 & 29.271 & 3.669 & 75.928 & 20.267 & 3.662 & 84.687 & 20.693 & 3.662 \\
\hline $\mathrm{B}_{0}$ & 3.852 & 41.688 & 3.388 & 1.705 & 28.613 & 3.379 & 1.298 & 27.813 & 3.369 \\
\hline$C_{0}$ & 71.513 & 38.701 & 3.625 & 46.719 & 24.418 & 3.551 & 65.589 & 22.931 & 3.595 \\
\hline$A_{1}$ & 55.520 & 32.284 & 3.569 & 94.422 & 24.421 & 3.732 & 97.725 & 21.925 & 3.707 \\
\hline $\mathrm{B}_{1}$ & 7.268 & 34.311 & 3.400 & 1.515 & 19.478 & 3.379 & 3.287 & 19.4134 & 3.377 \\
\hline$C_{1}$ & 42.279 & 35.844 & 3.523 & 49.686 & 19.374 & 3.562 & 35.105 & 20.199 & 3.488 \\
\hline$A_{5}$ & -44.062 & 26.463 & 3.220 & 59.753 & 26.207 & 3.600 & -55.553 & 17.221 & 3.171 \\
\hline$B_{5}$ & 10.471 & 36.999 & 3.411 & 16.083 & 24.935 & 3.434 & 15.966 & 23.640 & 3.421 \\
\hline$C_{5}$ & 8.393 & 33.509 & 3.404 & -43.559 & 21.678 & 3.208 & -34.087 & 19.619 & 3.246 \\
\hline$A_{10}$ & -27.963 & 29.995 & 3.277 & -55.686 & 15.968 & 3.162 & -41.338 & 21.928 & 3.221 \\
\hline $\mathrm{B}_{10}$ & -27.239 & 38.760 & 3.279 & -33.666 & 25.953 & 3.245 & -32.728 & 25.229 & 3.251 \\
\hline$C_{10}$ & -59.120 & 36.027 & 3.168 & -70.707 & 26.663 & 3.105 & -53.909 & 24.853 & 3.177 \\
\hline$A_{15}$ & -16.841 & 28.099 & 3.316 & -10.077 & 16.941 & 3.335 & -12.791 & 20.409 & 3.321 \\
\hline $\mathrm{B}_{15}$ & -13.211 & 36.525 & 3.328 & -18.011 & 21.267 & 3.305 & -18.522 & 21.609 & 3.301 \\
\hline$C_{15}$ & -13.691 & 35.477 & 3.327 & -9.669 & 20.220 & 3.336 & -5.993 & 19.631 & 3.344 \\
\hline Water & -6.162 & 31.663 & 3.34 & -2.338 & 15.147 & 3.34 & -0.975 & 14.691 & 3.34 \\
\hline
\end{tabular}

Table 6. $x^{2}$ for CT numbers.

\begin{tabular}{|c|c|c|c|c|c|c|c|c|c|c|c|c|c|c|c|}
\hline \multirow{3}{*}{$\begin{array}{l}\text { Energy } \\
(k \vee p)\end{array}$} & \multicolumn{15}{|c|}{$x^{2}$ to water } \\
\hline & \multicolumn{5}{|c|}{$149-500 \mu \mathrm{m}$} & \multicolumn{5}{|c|}{$74-149 \mu \mathrm{m}$} & \multicolumn{5}{|c|}{$\leq 74 \mu \mathrm{m}$} \\
\hline & $A_{0}$ & $A_{1}$ & $A_{5}$ & $A_{10}$ & $\mathrm{~A}_{15}$ & $\mathrm{~B}_{0}$ & $\mathrm{~B}_{1}$ & $B_{5}$ & $\mathrm{~B}_{10}$ & $\mathrm{~B}_{15}$ & $\mathrm{C}_{0}$ & $\mathrm{C}_{1}$ & $C_{5}$ & $\mathrm{C}_{10}$ & $C_{15}$ \\
\hline 80 & 0.95 & 1.03 & 0.75 & 0.31 & 0.25 & 0.49 & 0.55 & 0.29 & 0.20 & 0.12 & 0.31 & 0.92 & 0.67 & 0.29 & 0.05 \\
\hline 120 & 1.07 & 0.60 & 0.53 & 0.39 & 0.19 & 0.64 & 0.31 & 0.41 & 0.50 & 0.18 & 0.36 & 0.45 & 0.09 & 0.08 & 0.06 \\
\hline 135 & 0.69 & 0.47 & 0.27 & 0.10 & 0.08 & 0.53 & 0.71 & 0.33 & 0.06 & 0.05 & 0.52 & 0.88 & 0.22 & 0.09 & 0.04 \\
\hline Total $x^{2}$ & 2.72 & 2.11 & 1.55 & 0.80 & 0.52 & 1.66 & 1.57 & 1.03 & 0.77 & 0.35 & 1.18 & 2.25 & 0.99 & 0.47 & 0.15 \\
\hline
\end{tabular}

Int. J. Radiat. Res., Vol. 19 No. 4, October 2021 


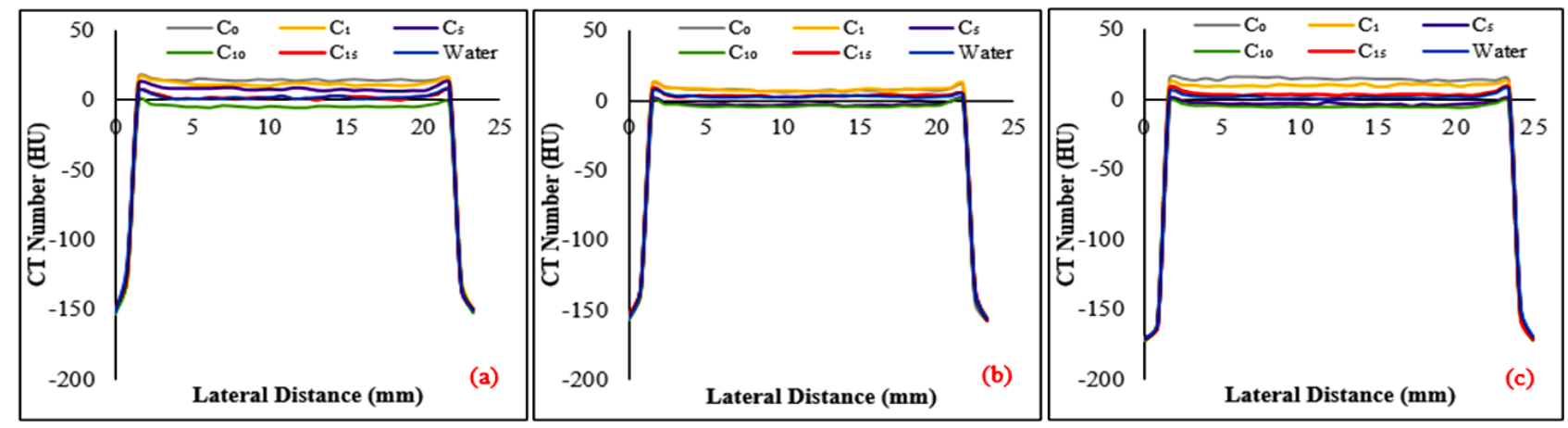

Figure 10. DDPs: (a) $80 \mathrm{kVp}$, (b) $120 \mathrm{kVp}$, and (c) $135 \mathrm{kVp}$.

\section{DISCUSSION}

As it can be seen, the difference between the primary and secondary structures of SPC does not significantly affect the thermal degradation process in a nitrogen atmosphere. The main reason for these observations can be explained through figure $3(a-b)$, which the denaturation of SPC promotes the intra- and inter-molecular cross-linking of amino acid residues, as well as the formation of disulfide cross-links and hydrophobic bonds (6).

The findings confirm the spectra of figure 4 (a), figure 4(b), and figure 4(c) absorption peak regions of the hydroxyl groups to be increased in the order of figure 4 (c) < figure 4 (b) < figure 4 (a) after treatment with IA-PAE owing to the high protein content in figure 4(c) (11). It was revealed that in SPC/NaOH/IA-PAE spectra, all essential structural absorption bands of SPC still demonstrated the absence of apparent chemical reaction between the adhesives.

It is worth pointing out that the sample of about $15 \mathrm{wt} \%$ IA-PAE and $\leq 74 \mu \mathrm{m}$ particle size are distributed much more homogeneously compared with the other selected samples. Furthermore, the maxima $\mathrm{Z}_{\mathrm{eff}}$ were observed for $\mathrm{C}_{15}$ with nearly the exact value to water. This shows that the presence of $\mathrm{NaOH} / \mathrm{IA}-\mathrm{PAE}$ adhesive breeds a uniform blend of SPC/R spp. compressed cell walls and ground parenchymatous tissues.

Herein, the studies show, SPC/R. spp. particleboard has an amorphous structure, while $\mathrm{SPC} / \mathrm{NaOH} / \mathrm{IA}-\mathrm{PAE} / R$. spp. exhibit crystalline structure as the highest crystallinity index with enhanced (101) and (002) peak intensity due to the increasing IA-PAE concentrations. This result is consistent with the result already obtained by other researchers $(6,7,9,10,17)$.

It is confirmed that the changes produced agrees toward the adhesion by mechanical anchorage, resulting in excellent structural stability, especially for the $\mathrm{SPC} / \mathrm{NaOH} / R$. $s p p$./IA -PAE (15 wt\%) ${ }^{6,8)}$. Moreover, at specific IA-PAE content, the WA and TS have been reduced by decreasing the particle size which is particularly important since such material, when used as a phantom, could be more resistant in the wet state.

Evidently, RAPs are affected by the chemical contents of the particleboard samples as well as incident photon energy; as the photoelectric effect plays a dominant role. Samples $A_{15}, B_{15}$, $\mathrm{C}_{10}$, and $\mathrm{C}_{15}$ exhibited the highest values of $\mu_{\mathrm{m}}$, while the HVL and MFP values of these particleboards were the lowest. This can be attributed to the more significant presence of high atomic number elements and thus provides greater radiation absorption ability.

It is apparent that the $\mathrm{C}_{15}$ exhibits substantially matchless performance due to the compact homogeneous surface and close interaction. In addition, higher X-ray CT tube voltage provides good density homogeneity and convenient DDPs to water as indicated by the lower relative standard deviation. The results achieved revealed the possibility of employing $\mathrm{C}_{15}$ as a reference in the development of TEPM for use in CT imaging studies.

Int. J. Radiat. Res., Vol. 19 No. 4, October 2021 


\section{CONCLUSION}

In conclusion, SPC/NaOH/IA-PAE/R spp. particleboard phantom with $15 \mathrm{wt} \%$ increment in IA-PAE addition level and particle size of $\leq 74$ $\mu \mathrm{m}$, show optimum qualities among the selected samples and was observed to be ideal for utilization in radiation dosimetry as TEPM.

\section{ACKNOWLEDGMENT}

The authors would like to acknowledge the financial aid of Research University grant no. 304/PFIZIK/6316173; 1001/CIPPT/8011001; 203/PTEKIND/6711525 by Universiti Sains Malaysia.

\section{Conflicts of interest: Declared none.}

\section{REFERENCES}

1. Khan FM (2010) The physics of radiation therapy. Lippincott Williams \& Wilkins, Philadelphia, USA.

2. DeWerd LA and Kissick M (2014) The phantoms of medical and health physics: Devices for Res. Develop. University of Wisconsin-Madison, Springer NY Heidelberg Dordrecht London, USA.

3. Ababneh B, Tajuddin AA, Hashim R, Shuaib IL (2016) Investigation of mass attenuation coefficient of almond gum bonded Rhizophora spp. particleboard as equivalent human tissue using XRF technique in the 16.6-25.3 keV photon energy. Australas Phys Eng Sci Med, 39(4): 871-876.

4. Bradley DA, Tajuddin AA, Che Wan Sudin CWA, Bauk S (1991) Photon attenuation studies on tropical hardwoods. Int J Radiat Applicat Intrumentat. Part A. Appl Radiat Iso- topes, 42(8): 771-773.

5. Liu C, Zhang Y, Li X, Luo J, Gao Q, Li J (2017) Green” biothermoset resins derived from soy protein isolate and condensed tannins. Ind Crop Prod, 108: 363-370.

6. Samson DO, Mat Jafri MZ, Hashim R, Sulaiman O, Aziz MZA, Yusof MFM, Shukri A (2020) Rhizophora spp. particleboards incorporating defatted soy flour bonded with $\mathrm{NaOH} / \mathrm{IA}-\mathrm{PAE}$ : Towards a water equivalent phantom material Radiat Phys Chem, 176(109057): 1-14.

7. Sara K, Farideh K, Petra N, Mats J (2010) Protein-based adhesives for particleboards. Ind. Crops Prod, 32(3): 275283.

8. Huang J and Li KC (2007) A new soy flour-based adhesive for making interior type II plywood. J Am Oil Chem Soc, 85 (1): 63-70.

9. Zhang $X$, Zhu Y, Yu Y, Song J (2017) Improved performance of soy flour-based adhesive with a lignin-based resin. Polym, 9(261): 1-10.

10. Gui C, Wang G, Wu D, Zhu J, Liu X (2013) Synthesis of a bio -based polyamidoamine-epichlorohydrin resin and its application for soy-based adhesives. Int J Adhes Adhes, 44: 237-242.

11. Anil NN and Trina GD (2019) Crosslinked thermoset resins and methods thereof. US Patent 10,179,807 B2.

12. Japanese Industrial Standard Particleboards (JIS A 5908) (2003) Standardization Promotion Department. Japanese Standards Association, 1-24.

13. Tursucu A, Demir D, Onder O (2013) Effective atomic number determination of rare earth oxides with scattering intensity ratio. Sci Tech Nucl Inst, 1-6.

14. Akkurt I and Canakci H (2011) Radiation attenuation of boron doped clay for 662, 1173 and $1332 \mathrm{keV}$ gamma rays. Int J Radiat Res, 9(1): 37-40.

15. Berger MJ and Hubbell JH (1987) XCOM: Photon cross sections on a personal computer. U.S. department of commerce, 1-10.

16. The Report of AAPM Task Group 220 (2014) Use of water equivalent diameter for calculating patient size and sizespecific dose estimates (SSDE) in CT. AAPM Task Group, 220: 6-23.

17. Mauri AN and Añón MC (2006) Effect of solution pH on solubility and some structural properties of soybean protein isolate films. J Sci Food Agric, 86(7): 1064-1072. 
